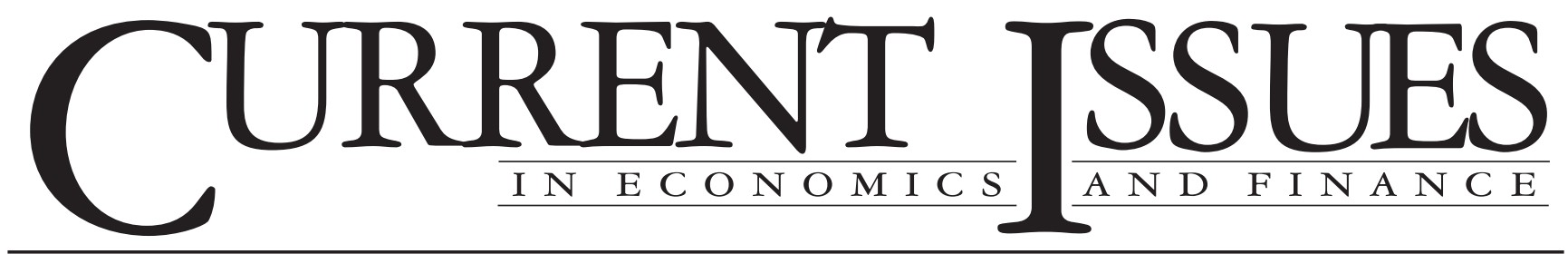

October 1996

Volume 2 Number 11

\title{
Has the Stock Market Grown More Volatile?
}

David Laster and Kevin Cole

The record number of fifty-point daily moves in the Dow Jones Industrial Average in 1996forty-five in the first three quarters alone-has attracted considerable media attention. An analysis traces this phenomenon to two basic causes: the record level of the Dow and the return of stock price volatility to post-World War II norms following several years of low volatility.

Large daily movements in the Dow Jones Industrial Average have occurred frequently in 1996. These gyrations, covered extensively by the business and popular media, have led some to conclude that stock prices have grown unusually volatile. One manifestation of this volatility is the frequency with which the Dow has closed up or down fifty or more points in a single day. ${ }^{1}$ Daily moves of this size - unheard of ten years ago and only an occasional occurrence until the start of this year-have become almost commonplace in 1996, occurring fortyfive times during the first three quarters.

Analytically, we can attribute the increased frequency of large daily moves in the Dow to two factors: an increase in stock price volatility (measured in percentage terms) and a rise in the Dow's level. Because the Dow has increased sharply in recent years-by more than 60 percent between 1992 and 1995 alone-a given percentage change in the Dow translates to many more points now than it did in the past.

This edition of Current Issues explores the recent volatility of the Dow Jones Industrial Average in the context of these two factors, focusing on January through September 1996. We show that although volatility has increased in 1996, this rise actually reflects a return to post-World War II norms from the unusually low volatility experienced between 1992 and 1995. We also examine the extent to which an increase in the Dow's level raises the frequency of large daily moves. Our analysis shows that when volatility is held constant, a doubling of the Dow's level causes a fivefold increase in the number of days on which the index closes up or down fifty points. ${ }^{2}$ A related exercise that allows for variations in stock market volatility over time reinforces these results. These findings suggest that daily swings in the Dow of fifty points, until recently an aberration, will continue to occur regularly.

\section{Market Volatility in Recent Years}

The market volatility of 1996 may have caught some investors by surprise because stock prices were unusually stable in the recent past. Following the extreme price movements of the late 1980 s, market volatility experienced a lull between 1992 and 1995 that accustomed investors to relatively modest stock price fluctuations.

Three Measures of Volatility. Three different measures of the Dow's daily volatility confirm that from 1992 to 1995 market volatility was at its lowest level in decades (Chart 1): ${ }^{3}$

- The standard deviation of daily price changes, a volatility measure commonly used by market participants, peaked at 2.17 percent in the tumultuous 1987 environment (panel A). It then declined sharply over the next several 
years, reaching 0.55 percent in 1995 , its lowest level in three decades.

- The Dow's median absolute percentage change, which represents the change in stock prices on a typical day, followed a similar pattern (panel A). It peaked most recently in 1987 and fell to a thirty-year low in 1995.

- A third indicator of volatility is the number of days on which the Dow registers a sizable change. In 1987, there were forty-one days on which the Dow was up or down 2 percent or more (panel B). Daily moves of this size occurred commonly through 1991 but then became far less frequent: there were only five 2-percent days in the 1992-94 period and none in 1995 .

Following the tranquil 1992-95 period, this year's volatility has been a rude awakening for some investors. Through September, standard deviation and median absolute percentage change were both up by about 50 percent from their 1995 levels, and the (annualized) number of 2-percent days had increased from zero to five. Is this simply a return to historical norms, as the three measures suggest, or is a new trend emerging?

Frequency Distribution of Returns. ${ }^{4}$ Another way to compare recent market volatility with past experience is to consider the frequency distribution of daily percentage changes in the Dow. For this comparison, our reference period will be the years 1946 to 1994. By sorting daily percentage changes in the Dow into size categories, Chart 2 allows us to compare the market volatility of 1995 and 1996 with this earlier experience.

First, we note how 1995 differed from the reference period. Small daily moves (of less than 0.5 percent) occurred on an average of 41.0 days per quarter in 1995, 6.6 days more per quarter than in the reference period. Conversely, the average number of large daily moves (of 1 percent or more) was just 4.3 per quarter in

Chart 1

Volatility Measures for the Dow Jones Industrial Average, 1946-96

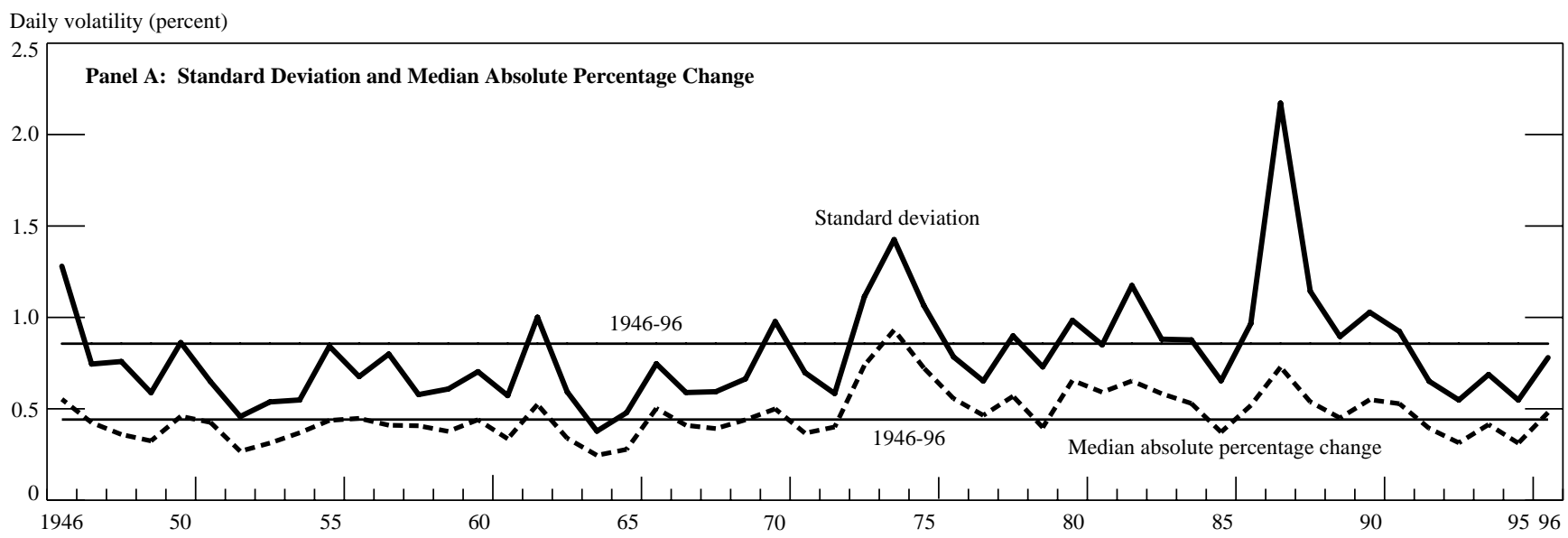

Number of days per year

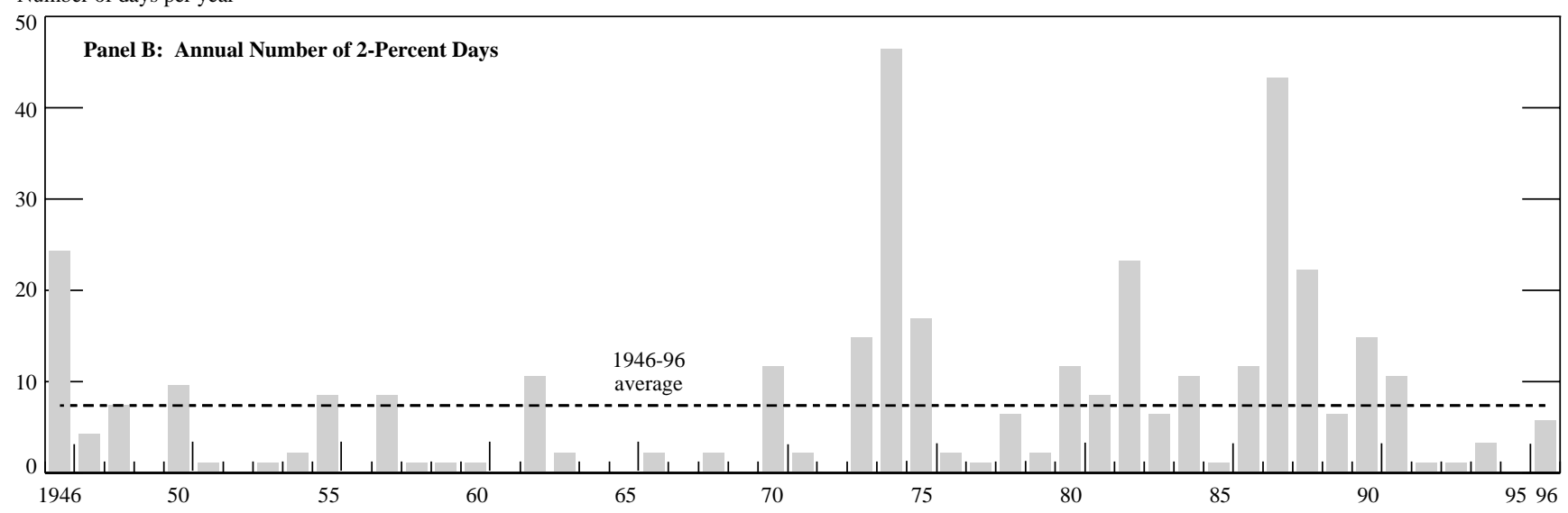

Source: Authors' calculations.

Notes: The horizontal lines in panel A represent standard deviation and median absolute percentage change computed for the overall $1946-96$ period. The figure for 1996 in panel B is for the first three quarters, annualized. 
Chart 2

\section{Distribution of Daily Percentage Changes in the Dow}

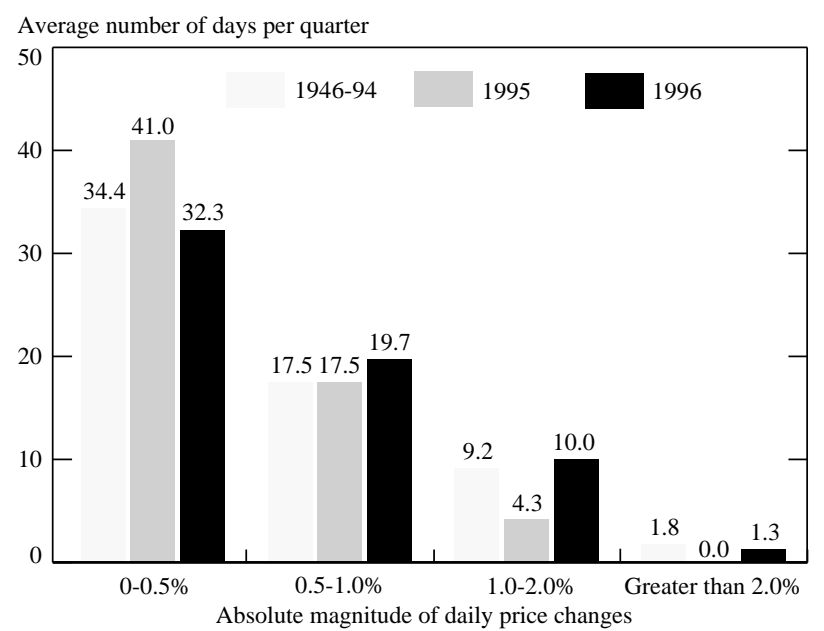

Source: Authors' calculations.

Note: Data for 1996 are for the first three quarters.

1995, compared with 11.0 for the reference period. Thus, in comparison with 1946-94, 1995 was an unusually calm year for the market.

Volatility in 1996 has been more typical of the higher levels of the past. Daily moves of less than 0.5 percent have been slightly less common in 1996 than in the reference period, while moves of 0.5 to 1 percent have been slightly more common. The number of large daily moves (1 percent or more) per quarter has averaged 11.3 in 1996, virtually identical to the historical average of 11.0. These results confirm that the Dow's volatility (measured in percentage terms) returned to historical norms in 1996 following a calm spell in $1995 .^{5}$

\section{Frequency of Fifty-Point Days}

When reporting the stock market's daily performance, the media generally focus on the absolute magnitude of changes in the Dow. To mirror this emphasis, we consider the frequency with which the daily change in the Dow has exceeded a fixed threshold of fifty points. (Movements of this size only started occurring ten years ago-the first such episode was on July 7, 1986, when the Dow closed down sixty-two points. Before 1986, the Dow traded at such a low level-never above 1600 - that daily moves of fifty points simply did not occur.) Between 1986 and 1995, the Dow's number of fifty-point days averaged just twelve per year and showed no sign of increasing. In 1996, however, there were forty-five such days in the first three quarters alone. What accounts for this upsurge?

The Impact of a Higher Dow. While the 1996 rebound in stock market volatility in percentage terms has increased the frequency of fifty-point days, the level of stock prices has also been a factor. The Dow climbed dramatically in 1995 and reached 5600 for the first time in February 1996. It fluctuated around that level for several months, until surpassing 6000 in October. To quantify the impact of a higher Dow on the frequency of fifty-point days, we consider the following question: If the distribution of daily percentage returns continued to resemble what it was over the past five decades, what relationship would exist between the Dow's level and the frequency of fifty-point days?

For this exercise, we use a Dow of 5600-the level that characterized much of 1996. If the likelihood of a given percentage move in the Dow were equal to its historical frequency in 1946-95 (Chart 3), then the probability of the Dow rising or falling by fifty points on a given day would equal the proportion of trading days in the historical period on which the size of the Dow's daily price change exceeded 0.89 percent $(50$ divided by 5600). Movements of this magnitude occurred on 2,672 of the 12,572 trading days in the historical period (Chart 3, shaded areas), or 21.3 percent of the time. We therefore estimate that when the Dow is at 5600 and volatility is at its historical level, a daily move of fifty points should occur with a probability of 21.3 percent, or roughly once a week.

This analysis can be repeated for other levels of the Dow as well. For example, the estimated probability of a fifty-point day when the Dow is at 2800, half as high, equals the proportion of days on which the Dow was up or down by more than 1.79 percent $(50$ divided by

\section{Chart 3 \\ Frequency Distribution of the Dow's Daily Returns, 1946-95}

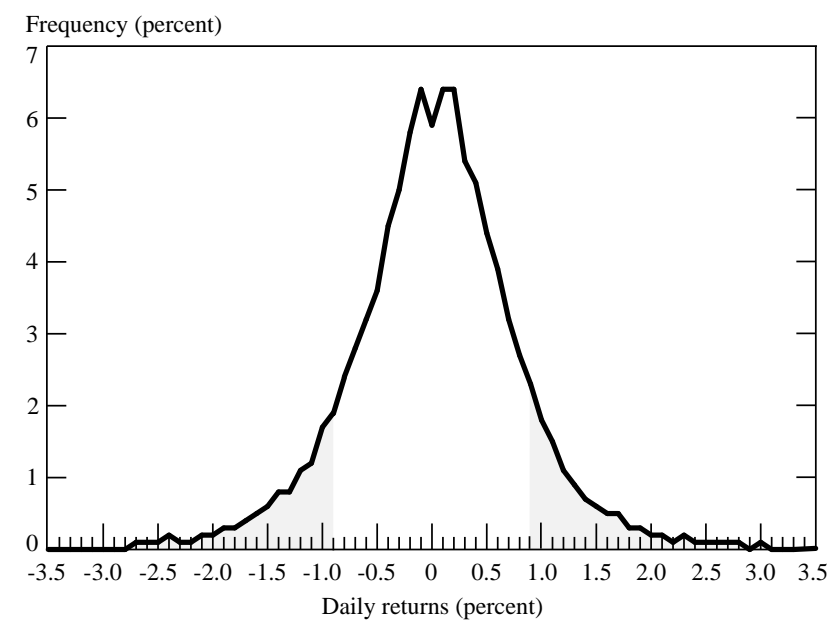

Source: Authors' calculations.

Notes: The shaded regions, representing days on which returns had an absolute value in excess of 0.89 percent, constitute 21.3 percent of the distribution. On fifty-two days, not shown here, absolute returns exceeded 3.5 percent. 


\section{Chart 4}

\section{Probability That the Dow Will Close Up or Down Fifty Points}

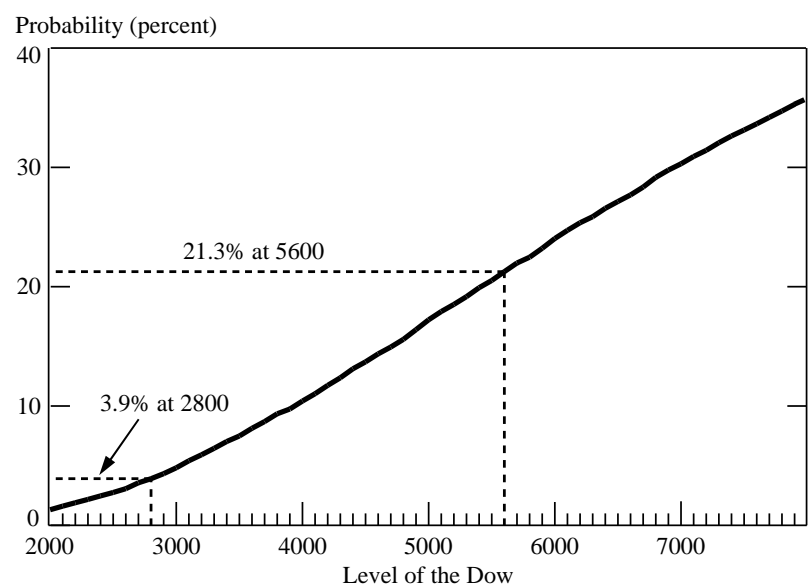

Source: Authors' calculations.

Note: Chart is based on the 1946-95 frequency distribution of daily returns.

2800). A move of this size, far less common, has an estimated probability of just 3.9 percent.

A comparison of these two estimates produces a strong implication: If the historical distribution of returns is an accurate guide to the future, a doubling of the Dow's level does not merely double the likelihood of a fifty-point day, it increases it fivefold. ${ }^{6}$ By repeating this exercise for a wide range of values, we can express the probability that the Dow will rise or fall fifty points on any given day as a function of its level (Chart 4).

Variations over Time. The extent to which daily returns vary is itself variable. Although Charts 3 and 4 depict the average frequency with which fifty-point moves in the Dow occur, they convey no sense of the extent to which this frequency varies over time. This variation is substantial. More than half of the days on which the Dow has closed up or down by more than 2 percent between 1946 and 1995 were concentrated in just six years: 1946, 1974, 1975, 1982, 1987, and 1988 (Chart 1, panel B). It is therefore useful to consider how volatile stock prices have been in different historical periods.

The calendar quarter is our unit of analysis. For each quarter from 1946 to 1995, we calculate the number of days on which the percentage change in the Dow was large enough to have caused the index at a given level to move at least fifty points. This approach allows us to use 200 quarters of market history as natural experiments that demonstrate the variation of stock price volatility over time.

First, consider how infrequently daily moves of fifty points would have occurred had the Dow been at a level of 2800_-where it stood in early 1990_-throughout the entire 1946-95 sample period (Chart 5, panel A). In the median calendar quarter of the sample (the quarter that ranks in the middle of the distribution), the number of days on which fifty-point moves would have been possible is only one. In addition, more than a third of the quarters (71 of 200) had no days that could have caused such moves, and nearly 75 percent of the quarters (146 of 200) had fewer than three days that could have accomplished this.

Repeating this analysis using a Dow level of 5600 offers a very different picture (Chart 5, panel B). The number of days per quarter on which fifty-point moves could have occurred is as high as forty-four; the median quarter has thirteen, or one per week. Seldom (in just 18 of 200 quarters) was this number below five.

Thus, had the Dow been at a level of 5600 throughout the post-World War II period, it would have experienced a high frequency of fifty-point days. How closely

\section{Chart 5 \\ Days with Percentage Changes Sufficient to Cause a Fifty-Point Move in the Dow: Quarterly, 1946-95}
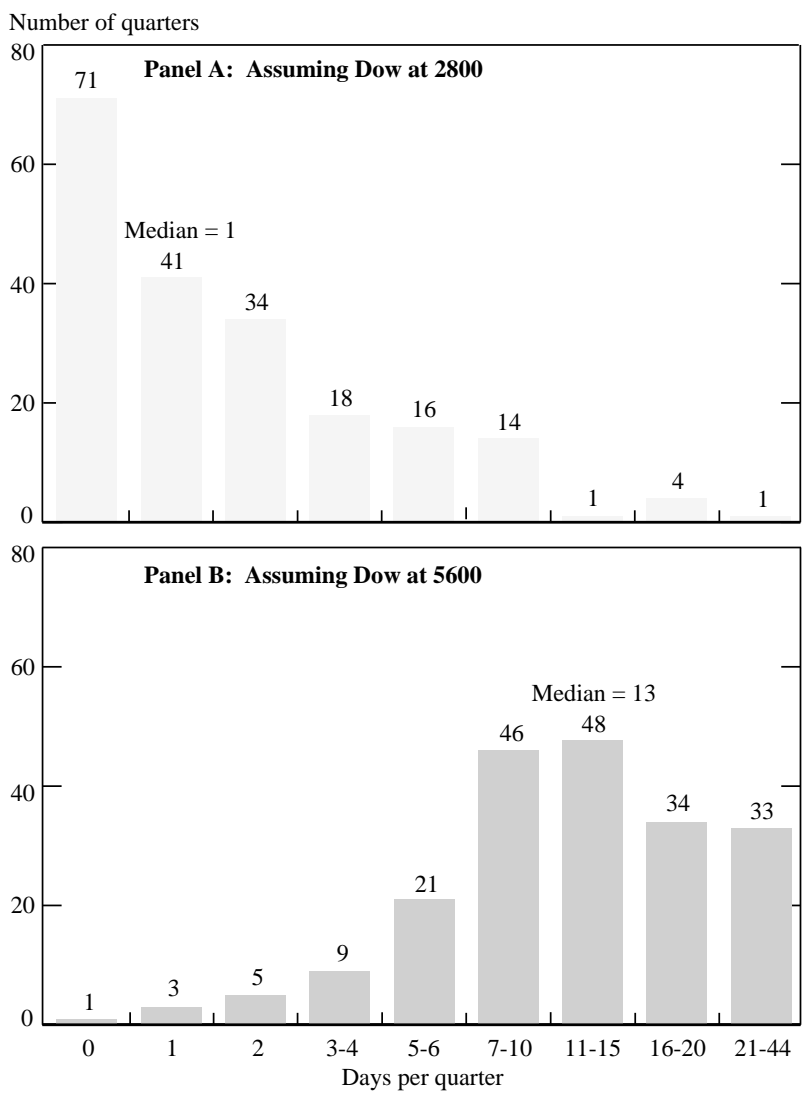

Source: Authors' calculations.

Notes: Panel A tabulates the number of days per quarter on which the Dow Jones Industrial Average closed up or down more than 1.79 percent $(50$ divided by 2800). Panel B tabulates the number of days per quarter on which the Dow closed up or down more than 0.89 percent ( 50 divided by 5600 ). 
does the Dow's performance in 1996 conform to this pattern? The Dow closed up or down fifty points on eighteen days in the first quarter. This level of volatility, while above the median, has ample historical precedent. Moreover, the number of fifty-point days in the second and third quarters, twelve and fifteen, respectively, was quite close to the median. In sum, this approach further confirms that volatility in 1996 has been typical of the postwar years.

\section{Disentangling Volatility from Price Level}

As we have noted, the frequency with which substantial daily moves in the Dow Jones Industrial Average occur depends on the Dow's level and its volatility in percentage terms. To evaluate the impact of each factor, we compare the actual number of fifty-point days that occurred each year with the number that would be expected to occur, solely on the basis of the Dow's level, under normal volatility conditions (Chart 6). ${ }^{7}$ From 1987 to 1991 , the number of fifty-point days generally exceeded these expectations because of the market's high volatility. In 1992-95, the Dow surged 61 percent to record levels, sharply boosting the expected number of fifty-point days. These expectations were not realized, however, because of an offsetting factor: the Dow's unusually low volatility during those years. So strong was the effect of this low volatility that, notwithstanding the Dow's much higher level, daily moves of fifty points were actually no more common in 1992-95 than they had been previously.

This year, as volatility has reverted to a level more

\section{Chart 6}

\section{Daily Moves in the Dow of Fifty Points or More}

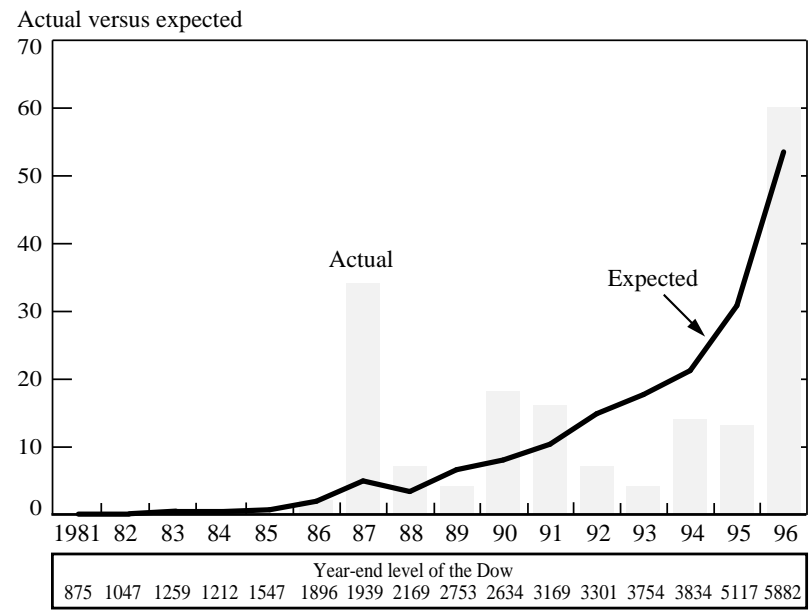

Source: Authors' calculations.

Notes: The 1996 data are for the first three quarters, annualized. The 1996 level of the Dow is for September 30. The expected number of fifty-point days is defined as the sum of the probabilities of fifty-point daily moves for each day of the year, as calculated in Chart 4 . typical of the past half-century, the frequency of fiftypoint days has risen markedly, to about its expected level. Seen in this light, the jump in the number of fiftypoint days in 1996 does not appear to be a temporary phenomenon. If this year's level of market volatility persists, we may only just be starting to feel the impact that record valuations of the Dow can have on the frequency of large daily moves.

\section{Conclusion}

Our analysis shows that the unprecedented frequency with which fifty-point moves in the Dow Jones Industrial Average have occurred in 1996 is due to two factors: the record level of the Dow and the return of stock market volatility to the higher level characteristic of the post-World War II years.

Although considerations such as business cycle effects and the direction in which stock prices have moved might help explain volatility, our focus has been on the consequences of market volatility, not its causes. We have shown how, given the historical distribution of percentage daily returns over the past five decades, a doubling of the Dow from its early 1990 level of 2800 to a level of 5600 has increased the probability of a fifty-point day more than fivefold.

If, as we find, daily moves of this size can be expected to occur approximately once a week at current stock price and volatility levels, intraday moves of this size will by definition occur at least as often. Analysis of the type presented here might therefore contribute to the ongoing discussion of the rules limiting computerguided trading on days when the Dow has risen or fallen fifty or more points.

\section{Notes}

1. This fifty-point threshold, though chosen arbitrarily for the analysis, has practical significance: it is the threshold at which New York Stock Exchange rules limiting computer-guided trading go into effect. We chose not to use a twenty-five-point threshold because moves of this size now occur so frequently that they are no longer noteworthy. Using a cutoff of seventy-five or a hundred points leads to results that are qualitatively similar to what we find using a fiftypoint threshold.

2. To simplify the discussion, we will refer to a price change of fifty or more points as a "fifty-point" price change.

3. The focus of this paper-why significant daily moves in the Dow Jones Industrial Average seem to have become more common in recent months - has guided our choice of data. We analyze the Dow's performance as opposed to that of other measures such as the Standard and Poor's 500 index because the Dow is the market index that the business and the popular media emphasize most. We use data on daily price changes, not intraday fluctuations, because these changes are reported most prominently in the media. 
4. For convenience, we will sometimes refer to percentage price changes as "returns," although the term "returns" is generally defined by market observers to include dividends.

5. A more formal statistical test-known as the Kolmogorov testallows us to reject with 99 percent certainty the hypothesis that returns for 1995 were drawn from the distribution observed for 1946-94 ( $\mathrm{D}=0.132 ; \mathrm{p}=0.0004)$. The test does not, however, reject this hypothesis for returns in January-September $1996(\mathrm{D}=0.064$; $\mathrm{p}=0.4252$ ).
6. This fivefold increase occurs for current levels of the Dow ranging from 5500 to 6000 and is even higher for levels of the Dow below that range. The result follows mechanically from the shape of the frequency distribution of daily returns depicted in Chart 3 . The key insight is that daily returns of a magnitude of 0.89 percent or greater have occurred far more than twice as frequently as have daily returns of double that magnitude.

7. The percentage probability of a fifty-point day was computed for each trading day of the year on the basis of the relationship shown in Chart 4. These figures were then summed for all the days of the year to arrive at the expected number of fifty-point days.

\section{About the Authors}

David Laster is an economist in the Capital Markets Function of the Research and Market Analysis

Group; Kevin Cole, formerly an assistant economist in the Function, is currently a Ph.D. candidate in economics at the University of California at Berkeley.

The views expressed in this article are those of the authors and do not necessarily reflect the position of the Federal Reserve Bank of New York or the Federal Reserve System.

\section{Recent Current Issues}

$\begin{array}{lcll}\text { Date } & \text { Vol./No. } & \text { Title } & \text { Author(s) } \\ 4 / 96 & 2 / 4 & \text { Core CPI: Excluding Food, Energy ... and Used Cars? } & \text { Peach, Alvarez } \\ 4 / 96 & 2 / 5 & \text { 1996 Job Outlook: The New York-New Jersey Region } & \text { Orr, Rosen } \\ 5 / 96 & 2 / 6 & \text { Understanding Aggregate Default Rates of High Yield Bonds } & \text { Helwege, Kleiman } \\ 6 / 96 & 2 / 7 & \begin{array}{l}\text { The Yield Curve as a Predictor of U.S. Recessions } \\ \text { Consolidation and Competition in Second District }\end{array} & \text { Estrella, Mishkin } \\ 8 / 96 & 2 / 8 & \begin{array}{l}\text { Banking Markets } \\ \text { Securitizing Property Catastrophe Risk }\end{array} & \text { Borden, Sarkar } \\ 9 / 96 & 2 / 9 & \begin{array}{l}\text { Repo Rate Patterns for New Treasury Notes } \\ \text { Seane }\end{array}\end{array}$

Readers interested in obtaining copies of Current Issues in Economics and Finance through the Internet can visit our site on the World Wide Web (http://www.ny.frb.org). From the Bank's research publications page, you can view, download, and print any edition in the Current Issues series, as well as articles from the Economic Policy Review. You can also view abstracts for Staff Reports and Research Papers and order the full-length, hard-copy versions of them electronically.

Current Issues in Economics and Finance is published by the Research and Market Analysis Group of the Federal Reserve Bank of New York. Dorothy Meadow Sobol is the editor.

Editorial Staff: Valerie LaPorte, Mike De Mott, Elizabeth Miranda

Production: Graphics and Publications Staff

Subscriptions to Current Issues are free. Write to the Public Information Department, Federal Reserve Bank of New York, 33 Liberty Street, New York, N.Y. 10045-0001, or call 212-720-6134. Back issues are also available. 